\title{
The public fountains of the City of Dijon
}

\section{By Henry Darcy, 1856, English \\ Translation by Patricia Bobeck}

Published by Kendall/Hunt Publishing

Company, ISBN 0-7575-0540-6, USD100.00

Today, Darcy's Law is commonplace in many aspects of hydrogeology, soil science, petroleum engineering, civil engineering, chemical engineering and other fields involving flow in porous media. It is indeed one of the most fundamental equations for predicting the flow of fluids in a porous medium. In my field of interest, hydrogeology, it describes the rates of groundwater flow in aquifers. Darcy is thus known to many scientists and engineers as a founding father in their disciplines. As a student of hydrogeology and now a teacher and researcher in the field, I have always been curious about Henry Darcy. Sure, I knew Darcy's Law and I knew that Darcy was forever remembered for it. But how much did I really know about Darcy and his work? I always felt that only the tiniest part of the big picture was being revealed and that so many pieces of the puzzle were either missing or did not fit. Most of the very limited knowledge I had gained about Darcy was about his law only and even that was gleaned reading regular hydrogeology text books. But these texts rarely, if ever, provide more than the equation for Darcy's Law and a discussion on cross-sectional areas, inflow and outflow tubes, manometers, and hydraulic conductivities (the modern term for the constant of proportionality in Darcy's Law that someone, but not Darcy, coined). But that's usually it! A few equations, a modern illustration of the column and its manometers, a brief explanation and an example problem and you're done. It is only relatively recently that some partial translations of Appendix Note D in Darcy [1856], most notably the section containing the famous column experiments, have been published such as that by R. A. Freeze in a collection of classic papers in hydrogeology for the Benchmark-Papers-in-Geology series [Freeze and Back, 1983]. But Darcy's report was some 650 pages long and contained 28 plates of figures. In fact, it was only in Part 2 of Appendix Note D on pages 590-594 of the original work in a subsection titled "Determination of the laws of the flow of water through sand" that directly related to Darcy's famous column experiments. That is only five pages about the column experiments at best. I could not help but wonder what other interesting and possibly unknown information might rest within the pages of Darcy's monograph, after all, 650 pages is a rather long piece of work! It also raised questions in my mind about Darcy and the process of his

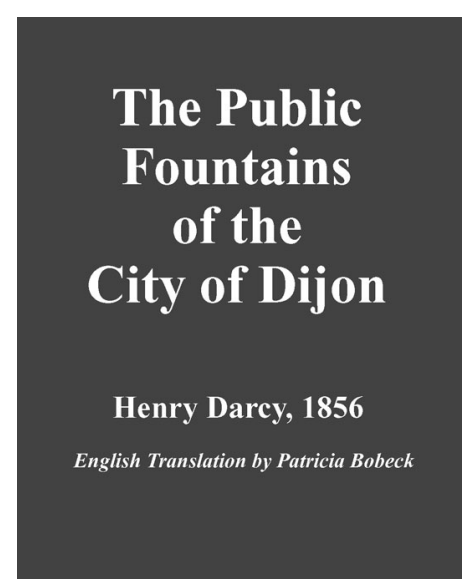

discovery, his motivations for the work, and so on, that at present are largely unanswered. Just some questions included, but were certainly not limited to: Did Darcy understand the significance of his law and interestingly, did he expect to obtain the result now known as Darcy's Law before he undertook his column experiments? Or even a more fundamental point for discussion, why exactly did Darcy undertake the column experiments in the first place?

It is widely known that Darcy published his most famous text on the construction of the municipal water supply of Dijon, "Les Fontaines Publiques de la Ville de Dijon" [Darcy, 1856] (this title is in fact an abbreviation of the very long title which by modern standards is indeed a mouthful!) whilst he was working as Inspector-General of the French Imperial Corps of Bridges, Highways, and Mines in Dijon and in recent years, a number of authors have written about Darcy's life and the process of discovering his law [e.g., Freeze, 1994; Brown, 2002; Simmons, 2003]. But Darcy's monograph was written entirely in French and probably could only be found in a handful of dusty archival collections around the world. Thus, the answers to these and other questions, in Darcy's words, were not easily accessible at all. The context, in which Darcy's Law, one of the most important governing equations in geoscience and engineering was discovered, was largely unknown. But that has now changed. Thanks to Patricia Bobeck's faithful English translation of the complete original French work, published by Kendall/Hunt, we are taken back in time into early 19th century science and engineering, into a world of vibrant fundamental scientific discovery and in particular, into Darcy's world. The answers to many questions can now be answered and many more intriguing insights and lessons are learned. Most importantly, they are learned directly from Darcy himself and we soon discover why it is that we honour this man with one of our most important fundamental governing equations.

Darcy's monograph shows how he approached the design and construction of the Dijon water supply system by choosing the water source, building an aqueduct and designing the water distribution system.
Darcy's goals were clear, his vision profound and his technical ingenuity fascinating even by modern standards. He set out to provide some 120 street fountains that would supply abundant free water for domestic purposes, for washing streets and sewers and in fire fighting. From very first principles, he designed and created the public fountains of the city of Dijon. He installed the street fountains at 100 metre intervals so that no one had to walk more than about 50 metres to get free clean water and in doing so turned a provincial capital rid with filth and squalor into a city with one of Europe's best water supply systems by about 1840 . It was purported to be second only to Rome at the time and occurred well in advance of even water supply development in Paris that was achieved by the mid 1860's. Darcy had brought about a major transformation for the lives of the people living in the city of Dijon that can hardly be understated. He himself noted that various books available at the time debated issues relating to water supply systems but that they did so theoretically and that "a publication that reports on the construction of a large distribution system would be of interest to engineers"

I found myself completely captivated by this book as I searched to learn more about the scientific roots of my profession, hydrogeology. Reading it afforded me a much deeper and now well-founded respect and appreciation for the father of my science Henry Darcy. The precise reasons for why Darcy was an amazing and incredibly talented scientist and engineer are now perfectly clear. The book provides irrefutable evidence in support of Darcy's outstanding capabilities, intellect and vision in both science and engineering. Darcy's deep knowledge of subject material spanning such wide discipline areas including geology, hydrology, architecture, engineering, policy, social science and economics is both truly amazing and impressive. His ability to integrate and apply such multidisciplinary areas is profound and this is still a challenge we face today as we continue to explore and manage an ever growing number of water and environmental phenomena and problems, both natural and anthropogenic. But what makes Darcy's contribution even more noteworthy is that he possessed all of these skills as an individual and that his work presents an approach to solving water supply and distribution problems that was a new field at that time. In reading the book, one is captivated by the breadth of the work he undertook in almost thirty years of his life. In fact, most of his life's work, but not all, is contained there. It is likely that Fontaines, his most famous work, was Darcy's attempt to write a "thesis" at a time of deteriorating health. He died in 1858 just a couple of years after it was published.

The monograph contains four parts and an appendix. Part 1 describes the historical situation with respect to Dijon and its water supply and discusses the Old Fountains dat- 
ing back to the end of the 16th century, the springs previously conveyed to Dijon, previous research conducted between the 15th and 19th centuries on the hydrology in the region and a detailed discussion on the steps taken to arrive at the choice of the Rosoir Spring, a beautiful and crystal clean cold water spring located some $10 \mathrm{~km}$ north of Dijon, for use as the town's water supply. It also discusses the origin of springs, ancient and modern methods of investigation used to discover them and a lengthy discussion on artesian wells. Part 2 describes his construction of the aqueduct used to convey water from the Rosoir Spring to Dijon and the internal water distribution system. It includes highly detailed technical information about the engineering infrastructure and a detailed cost analysis for the project. Part 3 contains the scientific detail of experiments that Darcy conducted on both the aqueduct and pipe distribution system and leads to a discussion on the principles and formulae to guide engineers in the calculations required for the establishment of a water supply system. Part 4 demonstrates Darcy's appreciation for the humanitarian controls on the project and implications of his work and details many administrative and judicial questions and other non-scientific problems encountered during the project. These included discussions on the expropriation of springs and of the land, water concessions and opposition raised by a number of mill owners who claimed to suffer as a result of the Rosoir spring diversion. The appendix contains eight notes including topics such as the water supply systems of London and other major French cities, artificial and natural filtration of water and a very detailed discussion on pipe manufacture. As already mentioned, Appendix Note D contains the column experiments that Darcy conducted in order to determine the empirical law that is now named in his honour. It also begins with a review of natural and artificial filters in England and France. A very notable feature of the book is that it comes complete with top quality reproductions of the 28 original plates illustrations which are masterful, beautiful and fascinating. This atlas, originally published as a companion volume to the French monograph, contains pictures of the detailed components of the water supply system and the original apparatus Darcy used for his experiments on water flow through sand. These plates are truly works of art. This then is the barest detail of the Darcy monograph.

What is important, however, is that the entire monograph and its complete discussion on the water supply project, provides us with the necessary information critical to appreciate the historical context of Darcy's Law. The book clearly shows that Darcy was extremely well read and was familiar with the important literature of the day. He also writes regularly throughout the monograph of the personal communications he had with other scientists, engineers as well as influential policy and decision makers in councils, scientific institutions such as the French Academy of Sciences, and Ministers in government. It demonstrates unequivocally that Darcy operated both at all levels from scientific, to engineering, to management and across many discipline areas. From the intricate designs of each pipe and valve in all the branches of the water distribution system to taking his own measurements on spring discharge and pipe flows, through to decision making, management and economic issues at the highest levels pertaining to his project, Darcy was working on it and thinking about it. He was bringing about change on a massive scale and dealt with all the challenges and problems, both technical and non-technical, that are still familiar to us today.

And what of the answers to the questions raised earlier about Darcy's Law? One finds those in curious places indeed. For example, in commenting on the results of the column experiment that led to his law, Darcy notes in footnote 4 of Appendix Note D "I had already foreseen this curious result in my research on water flow in conduit pipes of very small diameters, when the water velocity did not exceed 10 to 11 centimeters per second". Darcy was thus the first person to make a clear connection between flow in sand and flow in small pipes at low velocities. The book reveals that the sand column experiments were a mere confirmation of the law Darcy had already suspected. This point has been the subject of some speculation in previous literature [Freeze, 1994; Brown, 2002] but is confirmed by the Darcy text. Darcy also recognised that his finding was new and significant. This is noted by Darcy himself when he writes in his preface "I have not seen the documents that are included in Note D collected in any special book. In particular, to my knowledge at least, no one has experimentally demonstrated the laws of water flow through sand". Darcy's personal view on the significance of Note D is also enforced by the fact that he dedicates to it, almost half the length of his preface to his entire work. The book also describes very clearly the intention for the column experiments in a number of places which is primarily driven by the need to "decrease significantly the surface area of artificial filters" and the section of Note D on modifications to apply to filters begins with the statement "Now I would like to discuss a method of significantly increasing the discharge of filters per given surface area and as a result, facilitating the construction of this equipment that until now has required sites so large that the very choice of them was one of the major difficulties of large-scale filtration". In addition to the motivation for improved filtration methods and increased accessibility to such technology, Darcy also invoked his law to explain how the discharge of springs could be increased by lowering their levels. It is, however, in presenting data concerning the discharge of filters in England, Scotland and France, that Darcy's principal motivation is clarified when he writes "no general law can be deduced from this data, given that the nature and the thickness of the filtration sands are not comparable, that the heads are variable, and the water enters the equipment with different degrees of clarity. I have tried to use precise experiments to determine the laws of water flow through filters... The experiments show positively that the volume of water that passes through a layer of sand of a given type is proportional to the pressure and inversely related to the thickness of the layers crossed". Although Darcy uses the term pressure, it is clear that Darcy is referring to hydraulic head difference across the column since he separates out the pressure and elevation components of the head term in his equations. This points to what must have been incredible challenges in the translation process as well as the potential for misinterpretation since in many places terms such as pressure head, hydraulic head or head difference (loss) are used interchangeably and imprecisely. There are also a number of editorial errors in the text and figures that have been pointed out by previous authors [Freeze, 1994; Brown, 2002].

Darcy's work was therefore not without problems and in some places the scientific discussion is rather quaint, and probably expectedly so, by modern standards. For example, Darcy carried out his column experiments in a local hospital in Dijon and noted problems with a water hammer effect caused by oscillations in water supply pressure as users turned faucets on and off. In his field experiments, a lack of observation wells meant that Darcy did not observe the cone of depression associated with well drawdown that we now know to occur. He therefore did not appreciate the nature of radial flow to wells even in aquifers with fractures and conduits. Darcy's rather lengthy discussion on the work of well-known and popular water diviner of the day, Father Paramelle, leads to a strongly dismissive conclusion on water divining when he writes "It is obvious that there is no mysterious or magical process here, only a little bit of staging perhaps!". This together with his discussion of the Greek water cycle, where water flowed from the sea to the continents, convinces me that he was aware of the naivety and primacy of science in understanding water resources. It also paints a vivid picture of some of the commonly held non-scientific practices and beliefs that Darcy was up against at that time and therefore some of the barriers he faced in the process of his scientific discovery. Other more personal sides to Darcy are revealed in many places throughout the book. For example, and on a much deeper personal level, Darcy reveals reasons for dedicating some thirty years of his life to the water supply project in Dijon and makes his humanitarian belief in the public's right to clean free water clear when he says "A city that cares for the interest of the poor class should not limit their water, just as daytime and light are not limited". These, and other, examples of 
Darcy's personal views and beliefs add real color to his technical work. For me, they make it all the more interesting and provide moments where the reader really feels connected to Darcy. They are indeed a highlight of the book.

Patricia Bobeck's book opens up a world of enormous possibilities that were not previously possible because both language and availability are no longer barriers. The translation project was first suggested to Patricia in 1989 by Bob Kent who had dreamt of translating Darcy's work since at least that time. Bob recently retired from Geomatrix in Coast Mesa, California, where he worked as a geologist and groundwater consultant. Before that, he was a principlal of Underground Resources Management in Austin, Texas, where he became acquainted with Patricia. Bob Kent believed that it was so important that scientists and engineers should be able to read Darcy's entire work that he approached his employer, Geomatrix Consultants, for support and they agreed to provide funding for the translation and publication of the book. I believe that Geomatrix should be both acknowledged and commended for the decision to support this translation. The partnership of Patricia Bobeck and Bob Kent has provided a masterful translation of one of the pioneering works of science and engineering as we know it today. And one could hardly ask for a more qualified person than Patricia Bobeck to complete this translation task. She has a Bachelors degree in French from Rosary College (now Dominican University) as well as Masters degrees in both geology and linguistics from the University of Texas and the University of Michigan, respectively. She is currently a hydrogeologist and geologist with the Texas Department of Health.

Patricia's clear labour of love has brought Darcy's work and world back to life two centuries later. Importantly, Darcy's Law and the process of that discovery, once hidden mostly in dusty archival collections, are now accessible to millions of readers worldwide. This translation therefore has profound implications. To truly realise just how profound, one must realise that there are less than twenty copies of the French original in libraries in the United States. To undertake the translation, a copy of the book was borrowed on interlibrary loan and photocopied! The French text used was a 50\% photocopied reduction of the original and this created enormous difficulties in the translation process with many numbers and superscripts in the tables and equations being illegible. Bob Kent had to borrow an original copy of the book for Geomatrix staff to proofread the tables and equations which was clearly time consuming and tedious work. Many language and technical editors reviewed the book and the Foreword to the book is written by the eminent O. E. Meinzer award winning hydrogeologist John M. Sharp, Jr. The translation began in 1989 when Patricia translated one chapter of the book but much of the translation began in the year 2000 and took some three years of evenings and weekends, with countless hours spent on research and in consultation with scientific experts. When one sees the book, both its voluminous size and its intricate technical content, one can only begin to appreciate the enormity of the task faced by Patricia Bobeck. The tremendous patience and meticulous attention to technical detail required to see the translation through to completion are a testimony to Ms Bobeck's personal character as well as her technical abilities as both a scientific translator and scientist. I tried really hard to imagine the difficulties that must have been faced in the process of constructing this enormous translation - the lulls in motivation, possibly made worse by the dreaded question "Why am I doing this?" as one works feverishly to translate tables of data with tiny illegible characters in the dark hours of the night. I surmise that one cannot fully imagine the task of a translators trade, particularly when it is compounded by the fact that Darcy's text is a highly technical piece of engineering science that weighs in at 650 pages! If only you could put my text aside for just a moment and browse through the volume to see what I mean. One is left amazed, inspired and in awe.

I believe that we, as an engineering and geoscience community, are now forever in debt to Patricia Bobeck for the complete preservation of the Darcy historical record and for making Darcy [1856] in all its glory internationally accessible. Many of the messages contained in Darcy's work are just as relevant and perhaps even more important today than when they were first written. As scientists, engineers, water managers, policy makers and the community at large continue to deal with an ever growing number of challenges that face water supplies and environmental contamination across the globe in the 21 st century, Darcy's work offers many insights, lessons to be learned and guiding principles that will be of great interest to many. Most importantly, I believe readers will find this book a source of deep inspiration. The relevance and appeal of this book is not limited to the engineering and science communities. It will be of interest to scientific historians, architects and city planners and policy makers and also to many members of the well read community interested in earth and environmental science or even just the history of the science. I doubt Darcy would ever have imagined that some 140 years after his death, scientists and engineers would routinely apply his laws to so many problems in so many disciplines. I also doubt that he would ever have dreamed that his swansong, Fontaines, would one day be translated into English and republished for readers around the world to satisfy their curiosity about his work, life and law. For me, this book gives Darcy meaning. It makes one realise why we as a geoscience community are so fortunate to honour this man with one of our most important and fundamental governing equations and why for many, we call Darcy the founding father of our science. As this book will attest, he was a scientist who made everlasting contributions to mankind. I am therefore both honoured and excited to commend this volume to you. Patricia Bobeck's translation is truly amazing and it is an intriguing read. Even if you don't own it yourself, it is a must volume for any engineering and geoscience library collection so please let your librarians know about it today.

\section{Acknowledgement}

I would like to thank Dr Glenn Brown for his very useful suggestions that helped in the preparation of this article.

\section{References}

Brown, G. O., 2002, Henry Darcy and the making of a law, Water Resources Research, 38(7), doi:10.1029/2001WR000727.

Darcy, H., 1856. Les Fontaines Publiques de la Ville de Dijon, Dalmont, Paris.

Freeze, R. A., and Back, W., eds, 1983, Determination of the laws of flow of water through sand, Translation by R. A. Freeze, in Physical Hydrogeology, Benchmark Papers in Geology, v. 72, pp 14-20, John Wiley, New York.

Freeze, R. A., 1994, Henry Darcy and the fountains of Dijon, Ground Water, 32, 23-30.

Simmons, C. T., 2003, Happy 200th birthday Mr Darcy and our thanks for your law! A tribute editorial celebrating the life and times of the father of our science, Henry Darcy (1803-1858), Hydrogeology Journal, v. 11(6), pp. 611-614.

\section{Craig T. Simmons}

School of Chemistry, Physics and

Earth Sciences

Flinders University

GPO Box 2100, Adelaide, SA

AUSTRALIA 5001

craig.simmons@finders.edu.au 